\title{
RASCH MODEL APPROACH FOR ANALYSIS OF MISCONCEPTION ON CHEMISTRY LEARNING WITH DISTRACTOR ANALYSIS
}

\section{Sri Mulyani* ${ }^{*}$ Nur Haniza Khoiriyanti, Lina Mahardiani, and Dimas Gilang Ramadhani}

Chemistry Education Study Program, Universitas Sebelas Maret Jl. Ir. Sutami No 36 A, Surakarta, Central Java 57126, Indonesia

* Correspondence: email: srimulyaniuns@staff.uns.ac.id

\section{ABSTRACT}

Multiple-choice questions can be used to identify misconceptions through distractor analysis. Distractor analysis for identifying misconceptions using Rasch modelling to find out how students choose options and whether they have any misconceptions. The test instrument uses questions from the teacher association in Indonesia to assess students' ability to master chemical contexts. The number of question items used is 35 and has been validated and tested for reliability to be feasible to use. Questions were given to 462 first-year high school students. The fit item analysis results show that there are several questions related to clothing that indicate misconceptions. This is supported by the distractor analysis value, which found that misconceptions indicate questions related to electrolysis, the incidence of colligative properties in daily life and the factors that affect corrosion. The distractor's value and the option probability curve are used to see how students know the ideas offered. The analysis results found that the material in the form of concepts and their application showed a large misconception, in which students would find it difficult to combine concepts and their applications.

Keywords: Rasch model, distractor analysis, misconception

\section{INTRODUCTION}

Chemistry studies matter, its properties, how and why substances combine or separate to form other substances, and how substances interact with energy [1-2] in symbols, commonly known as several representations [3]. Chemistry is defined as something abstract due to these three things, which causes a comprehensive understanding of chemistry [4]. Understanding basic chemistry concepts is essential for almost every profession. Chemistry is a part of everything in our life [5].
To understand chemical concepts, students often get information from a world outside of their cognition. Some of these concepts create misconceptions because understanding chemistry consists of macroscopic, sub-microscopic and symbolic concepts. Students may experience misconceptions to connect the three concepts [6]. A misconception is a problem in chemistry learning because it occurs for various reasons. Therefore, analysis of misconceptions in understanding chemistry is needed to improve learning quality. Previous 
research has identified misconceptions through open-ended tests that describe students' concepts more deeply through direct descriptions [7]. The next problem will arise if the number of participants to be assessed on a very large use of analysis with questions with various levels is one way to overcome open-ended questions' limitations. This is indeed better able to solve the problem with large number of respondents to be analyzed. Still, the analysis of misconceptions takes a long time and is more difficult, especially in analyzing and developing test instruments. Analyzing misconceptions using open-ended questions or tiered questions such as two-tier, three-tier confirmation is often added back to ensure that misconceptions occur [8] take a lot of time and are complicated.

Classical tests look at how misconceptions are assessed by relying on scores, such as using a two-level test or using qualitative methods with open-choice questions. Problems will arise when more and more students are analyzed. Another problem is with many respondents, which will be very difficult to diagnose if you have to do one by one, which is a misconception and which is not. The biggest problem is that tests such as two-tier and open-ended cannot describe the relationship between items and respondents [9]. Measurement of misconceptions using the Rasch model applies an approach to analyzing distractors through probability options. The Rasch model will assess the respondent's distractor's probability and compare it with Low-ability students and high-ability students. In general, the probability option's value will increase from the least selected option to the answer option [10-11]. Questions that are classified as difficult must be selected by students with high ability students and cannot be chosen by low ability students. Suppose that the correct answer gets a lower score than the other distractors. This means that difficult questions can be answered by students with moderate abilities but cannot be answered by students with high abilities and vice versa. This indicates that the item is problematic, or it can also be identified as a misconception [12].

The classical theory of determining misconceptions is based on identification at the individual and question level. To determine the tendency of misconceptions that occur on a large scale, a more precise method is needed [13]. Descriptive analysis, for example, open-ended questions on a small scale and identifying misconceptions at the individual level on a large scale, will certainly be tough [14]. Using the Rasch model will help to analyze misconceptions more precisely and more quickly on a large scale [15]. The Rash model will help identify and analyze more deeply, especially assisted by analyzing the distractors used and the pattern of answers obtained [16]. The use of distractor analysis is still not familiar to use for misconception analysis. In contrast, we can use a multiple-choice test, which is easier in instrument development and takes less time and can cover many respondents. This analysis can help in analyzing misconceptions more quickly and easily so that it can provide a new perception regarding how the analysis of misconceptions is easier, can cover many respondents, and quickly. 


\section{METHODS}

\section{Analysis}

The research method used was a quantitative approach using a Rasch model analysis. The Rasch model illustrates when a respondent $\left(B_{n}\right)$ answers an item $\left(D_{i}\right)$. This relationship will be expressed by the natural logarithmic (In) of the respondent who correctly answers the item $\left(P_{n i}\right)$ divided by the probability of the respondent not answering the item correctly $\left(1-P_{n i}\right)$. For true/false tests, the Rasch mathematical model (equation (1)) uses a single variable, the respondent's location along with the variable, and the test item's location along with the variable.

$$
B_{n}-D_{i}=\ln \left(P_{n i} / 1-P_{n i}\right)
$$

$B_{\mathrm{n}}$ is the ability of the test taker along with the variables; $D_{\mathrm{i}}$ is the difficulty of the test item; $P_{\mathrm{ni}}$ is the probability of the test taker correctly answering the certain test items; and $1-P_{\text {ni }}$ is the probability of one of the test takers answering incorrectly one of the test items [15].

The misconception analysis was obtained from the distractor analysis on multiple-choice questions by looking at the pattern of answers of the participants or the probability items used as a basis for determining the misconceptions that occur. Besides, the analysis used is to determine the item fit of each item, where the item that exceeds the specified limit is assessed as a matter that has the potential to produce misconceptions. The limits specified are [17]

- Outfit of mean square (MNSQ) value obtained: $0.5<\mathrm{MNSQ}<1.5$
- Outfit value of Z-standard (ZSTD) value obtained: $-2.0<$ ZSTD $<+2.0$

- Point Measure Correlation (Pt Mean Corr) value: $0.4<$ Pt Measure Corr $<0.85$

\section{Participant and instrument}

Participants who took this test were 462 students from various schools in the city of Surakarta, Indonesia. The test took place in 2019 with topics such as colligative properties, redox reactions, and electrochemistry. Students who take the test have studied the topic; we assume that they have understood the topic. The instrument used in this study was for students in the 3rd year of high school who have received this material in odd semesters. The questions made included the topics of colligative, redox and electrolysis. The teachers' association in Indonesia made this question to find out the final ability of students on this material in all schools, especially in the city of Surakarta. Test instrument in the form of multiple choice with 35 questions. This test is designed to be done in 120 minutes. Previously tested the validity and reliability with the construct validity number 0.87 and 0.92 reliability. This test instrument is suitable for use and assesses students' abilities on the topic that has been planned. We started a step by using this test instrument to assess student's abilities in the three topics and the level of misconceptions in the concept.

\section{RESULTS AND DISCUSSION}

The test instrument used was from the chemistry teacher association in Surakarta. Before we tested the instrument on students, we first analyzed its reliability and validity 
values using the Rasch model. The Pearson's reliability value found is 0.82 , and the item reliability value is 0.96 . Meanwhile, the Cronbach Alpha value as the relationship between items and persons shows a value of 0.85 . Based on the reliability value can be concluded that the reliability of the instrument is classified as special or very good [18].

The one-dimensionality value, known from the raw variance value, is $46 \%$. This shows the value of the variance instrument, and the validity results are good because it has a value greater than the threshold level, $40 \%$. The value of unexpected variance should not be more than $15 \%$. Based on the construct validity data obtained, there are no unexpected variants that exceed $15 \%$, and the raw variance value is more than $40 \%$. We can say that the instrument good construct validity, and the items can measure the diversity of respondents' abilities so that it is feasible for use [15].

\section{Value of item fit and item map.}

Based on the results obtained from the analysis of the item map on Figure 1, the persons are divided into 3 groups of abilities: low, medium, and high (on the left side of a vertical line). Item maps are divided into 4 groups: very difficult, difficult, medium, and easy (on the right side of the vertical line). This division is based on the separation produced by each category. This map variable data are used to see the location of items in the distribution of the item's difficulty level and its relationship with the person. Item number 25 (S25) has a high level of difficulty, so the students miss this item. Although S25 is a difficult item, it cannot be claimed directly as an item containing misconceptions. This is the same as items number 3 and 17 that cannot be classified directly as misconceptions because their item fits and distractors must be further [11].

Item fit can be used as a way not only to judge whether an item is good or not but also to initially analyze the items that are suspected as misconception items [11] . Item fit is based on the suitability of the items with the standard model used. In other words, we judge whether the item functions normally or not measurements. If an item does not fit (misfit), it indicates a misconception of the item's person. Some items have turned out to be classified as intermediate but not fit, which can be caused by only one group of people with certain abilities who can answer [19].

Items number 26 (S26) and 5 (S5) are identified as misfit items outside the fit statistics area. These items can be categorized as unusable items because they contain misconceptions or only be effective in only one group. Further use related to the analysis of misconceptions that occur will be better if you also look at the distractor's value If, in this case, we only see which items are ineffective, the next will be deeper to see whether the distractor can describe the level of students' conception ]20]. 


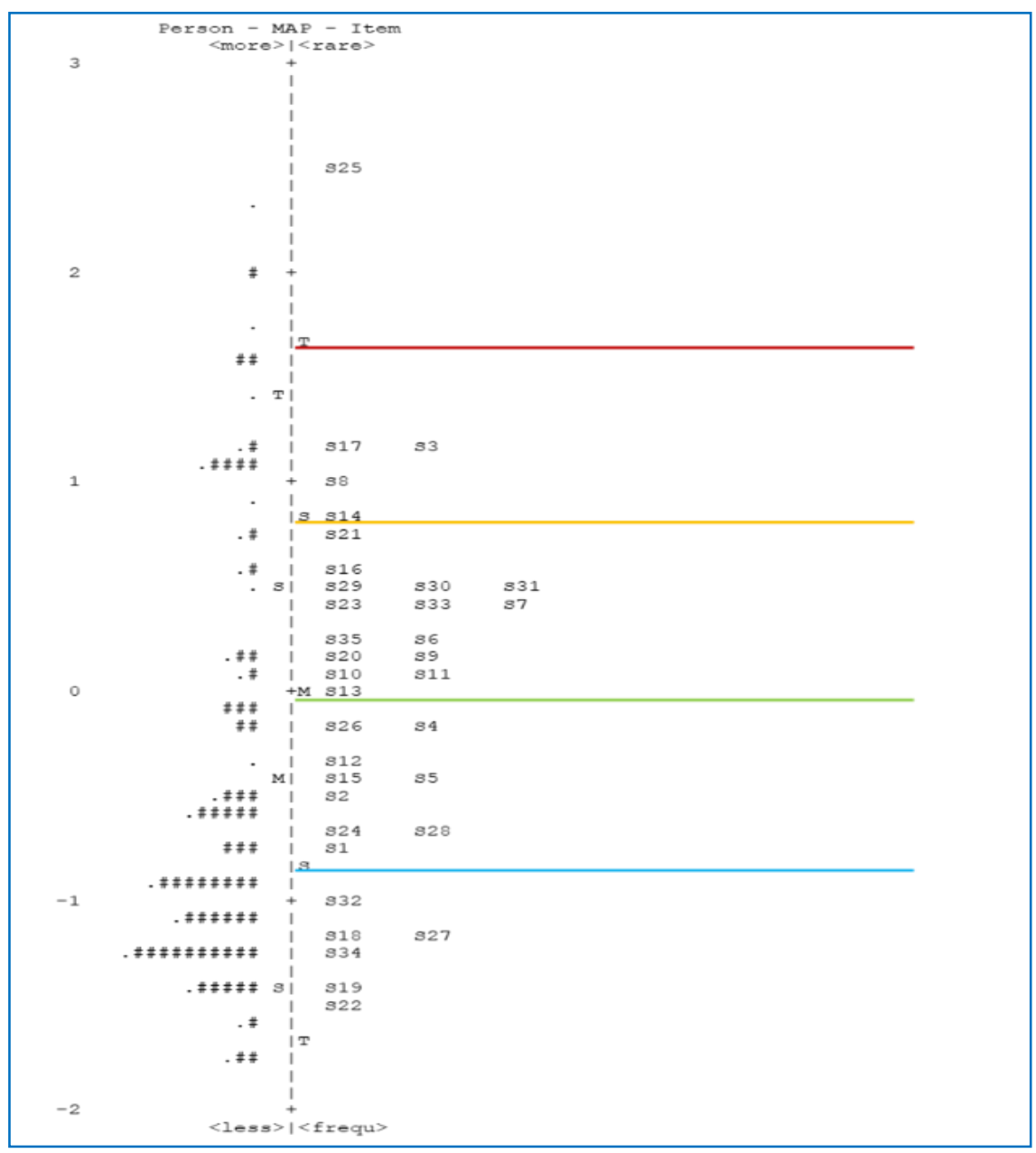

Figure 1. Item map using Rasch model analysis. $\mathrm{S}$ represents item; $\mathrm{S} 25=$ item number 25; Symbol '\#' represents 6 persons and symbol '.' for 1 to 2 persons.

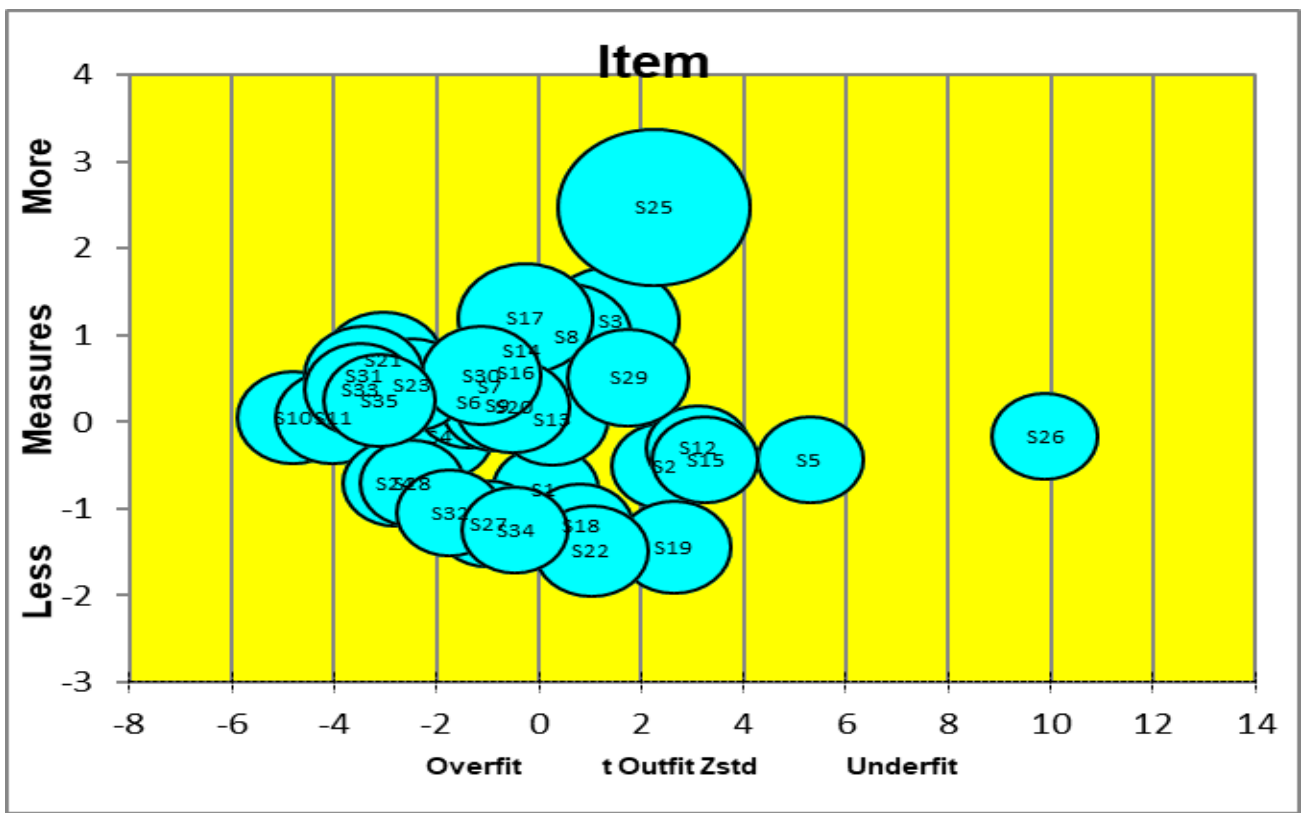

Figure 2. Item map of the RASCH analysis result 


\section{Distractor analysis}

In the multiple-choice test for cognitive tests, the effective use of a distractor to distract the participants' concepts can be identified from the change in the average logit of the test participants. The logit value will indicate the change in value from the distractor in the smallest to the largest order for the rarely chosen option to the correct answer value. The value always increases. If the value is known to the contrary or the correct option is at the bottom, this indicates that a misconception exists based on the distractor analysis [11].

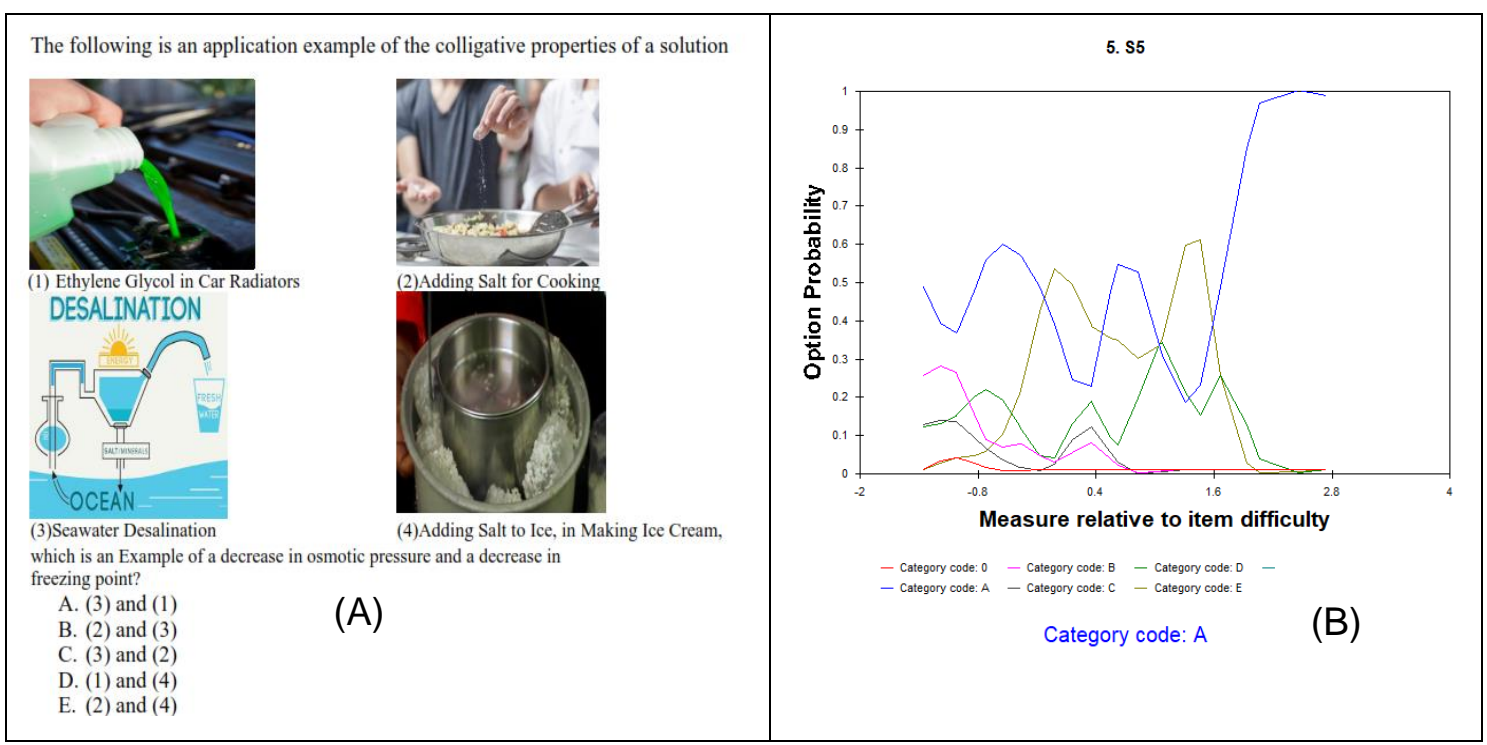

Figure 3. The distractor analysis (B) for item number $5(A)$.

There are five nails that are inserted into five glass containers, each container is

treated by adding lemon juice, boiling water, water, air, and cooking oil.

25. $\mathbf{S 2 5}$

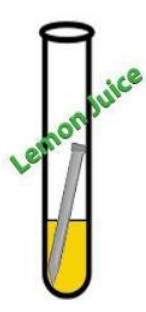

1

hich nail will rust the fastest?

A. (1)

B. (2)

C. (3)

D. (4)

E. (5)

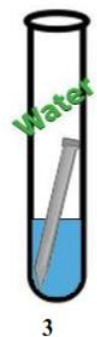

3

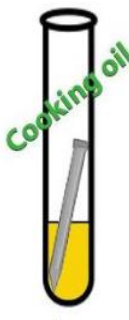

4

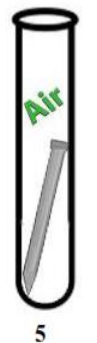

(A)

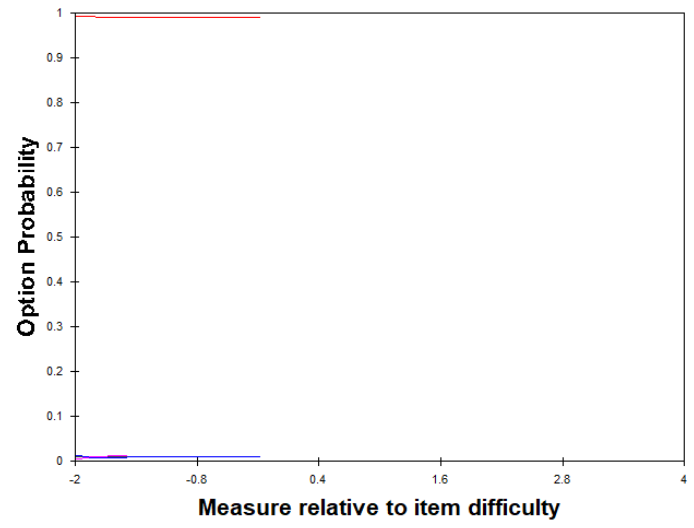

(B)

Figure 4. The distractor analysis $(B)$ for item number $25(A)$. 

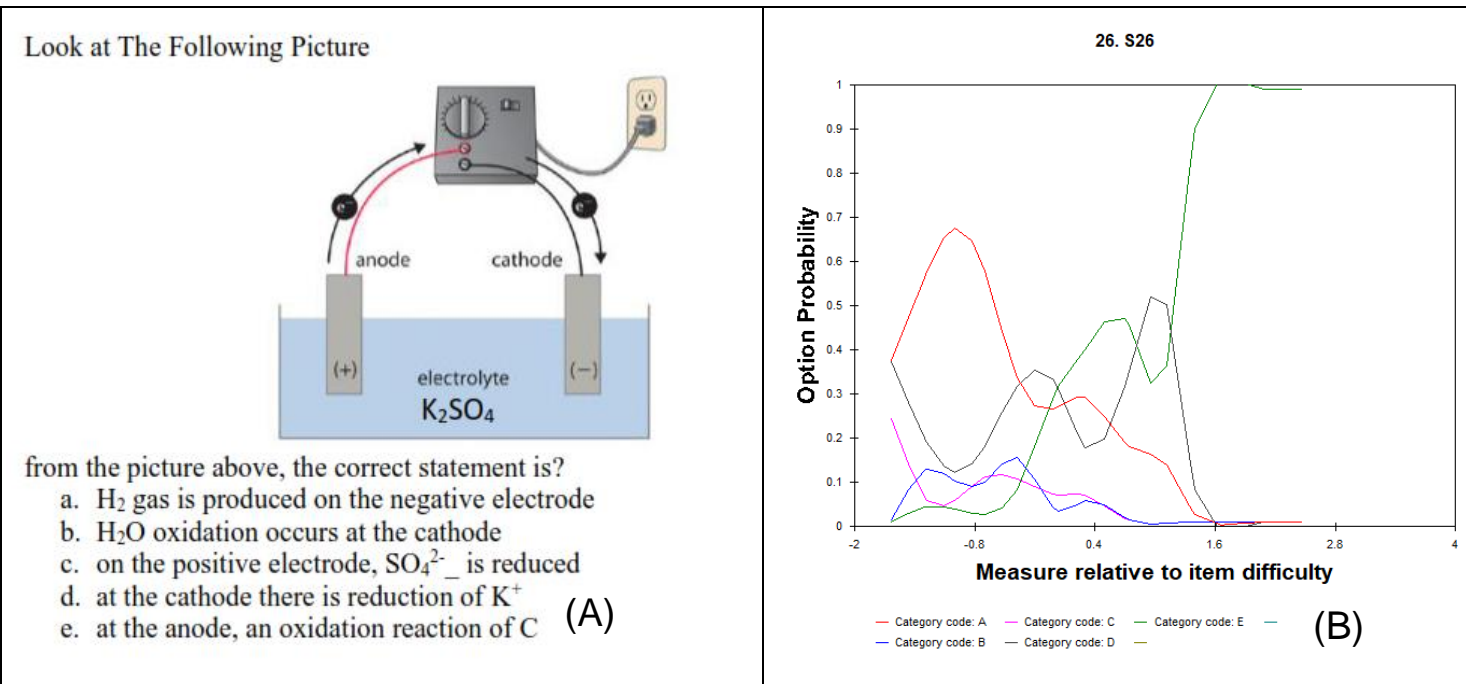

Figure 5. The distractor analysis (B) for item number $26(\mathrm{~A})$.

Item number 5 (S5) discusses the application of the colligative nature of solutions in daily life. As we know that the colligative nature of solutions in chemical concepts includes a decrease in freezing, an increase in boiling points, and a decrease in vapour pressure and osmotic pressure. The concept of this material is how the solutes can affect the original nature of the solvent. The addition of solutes is widely used in life, especially in the industrial field. One example of osmosis pressure application is seawater desalination, which is the purification process of seawater. This purification is done by applying pressure to the surface of seawater, whose value is much greater than the sea water's osmotic pressure. This pressure will force water to seep from salt water into pure water through a semipermeable membrane and leave ions in seawater that cannot pass through this membrane. This concept is still unfamiliar to students, so it will be difficult to understand and be misinterpreted. The term desalination is thought to be related to a decrease in the boiling point instead of osmotic pressure. An error causes this misconception in understanding the term desalination and seawater identical to salt. Students also think that things related to temperature always have a relationship with temperature. The textbook explanations illustrate that the freezing point is something related to salt used to reduce the freezing point of ice [21].

On the one hand, only a few students know ethylene glycol's function car radiators. Ethylene glycol is used to reduce heat in cars. In a region with four seasons, the water in the radiator will easily freeze [22]. The radiator with frozen water will certainly affect the performance of the engine. Ethylene glycol serves to reduce the freezing point so that the radiator water will be more difficult to freeze [23].

It is shown in Figure $3(B)$ that options $C$ and $D$ work very well to outwit students. They experience confusion in choosing between options $A, C$, or $D$ because they have problems determining scientific terms that are unfamiliar such as desalination and the use of ethylene glycol. The misconceptions occur mainly because the 
students are less able to recognize terms and phenomena so that students experience misapprehension in determining the application of the colligative the solution.

Item number 25 (S25) is categorized as the most difficult question. From the analysis results, even from the high groups, no one can answer this question. This misfit question may be caused by its difficulty level that is too high. Figure 4 (B) shows that $B$ and $B$ options confuse students with their basic concepts about rusting. Students choose options $\mathrm{A}$ and $\mathrm{B}$ more than option $\mathrm{C}$, which is the correct answer.

Options A and B in Figure 4 (A) are conceptually intended to assess students' understanding of the basic concepts of rusting by giving them the choice of replacing water with acid for option $A$ and with boiling water for option $B$ as we know that rusting will occur more quickly in the presence of oxidation reactions initiated by oxygen and water. The more $\mathrm{O}_{2}$ and $\mathrm{H}_{2} \mathrm{O}$ contents, the faster rusting will occur. Acid gave in tube number 1 (options $\mathrm{A}$ ) theoretically shows that the oxidation reaction will be inhibited because the dominant content in the acid is $\mathrm{H}^{+}$. Simultaneously, $\mathrm{O}_{2}$ and $\mathrm{H}_{2} \mathrm{O}$ will be more difficult to penetrate the acid solution so that the oxidation reaction will run slower. Option $B$ shows the difference between boiling water and unheated water is the $\mathrm{O}_{2}$ content in it. Boiling water has less $\mathrm{O}_{2}$ content than unheated water does because the heat generated will loosen the hydrogen bonds between water molecules, which causes this compound to release some oxygen and some minerals present in the water [24].
Misconceptions occur due to the students' misunderstanding of the basic differences between boiling water and the water that does not experience the healing process. They assume that heating water will make iron rust fast, but they do not realize that the heating effect will reduce oxygen levels in the water to hamper the rusting process. Meanwhile, the acid that slows down the rusting process is considered a compound that can accelerate the rusting process. The students' conception related to the process of rusting still brings up several misunderstandings due to their misperceptions about the content of $\mathrm{H}^{+}$in acids and the reduction in $\mathrm{O}_{2}$ levels caused by heating. The choice of the options with differences in treatment or the addition of substances that the students are not familiar with proves the be effective in determining the levels of students' misconceptions.

Item number 26 (S26) is identified as an item containing a misconception. The value of ZSTD, MNSQ indicates this. The Pt measures Corr value that exceeds the standard value and the value of the distractor points where the correct option has the average ability value that is not the same as questions 5 and 25. Question 25 has the toohigh level of difficulty, while questions 5 and 26 have the same case, namely misfit and the average ability value of the distractor used.

\section{CONCLUSION}

Misconception analysis does not require a specially modified test instrument. The analysis can be performed using a test instrument in multiple-choice questions, as is widely used by teachers. The misconceptions 
existence can be analyzed through distractor analysis of several questions. In the colligative nature material, it is evident that the students cannot express the initial concepts when given new terms they do not understand, which causes a misconception. In the material of oxidation and reduction, the error in assessing that boiling water has a higher oxygen value and acid can accelerate rusting results in the students' misconceptions.

\section{ACKNOWLEDGEMENTS}

This work was supported by the LPPM UNS under Grant of the Hibah Mandiri Aktif.

\section{REFERENCES}

[1] J. Sjöström, F. Rauch, \& I. Eilks, Chemistry education for sustainability. Springer: London, 2015. doi:10.1007/978-94-6300-175-5_9

[2] V. Albe, "On the road to science education for sustainability?". Cultural Studies of Science Education, vol.8, pp.185-192,2013. doi:10.1007/s11422-012-9449-4

[3] M. Burmeister, F. Rauch \& I. Eilks, "Education for Sustainable Development (ESD) and chemistry education". Chemistry Education Research and Practice, vol. 13, pp. 5968, 2012. doi:10.1039/C1RP90060A

[4] A. Basheer, N. Kortam, N. Zahran, A. Hofestein, \& M. Hugerat, "Misconceptions among Middle School Students Regarding the Conservation of Mass during Combustion, EURASIA J Math Sci Tech Ed, vol. 14, no.7, pp. 3109-3122, 2018. doi:10.29333/ejmste/91664
[5] S. Böschen, D. Lenoir, \& M. Scheringer, "Sustainable chemistry: Starting points and prospects." Naturwissenschaften, vol. 90, pp. 93102, 2003. doi:10.1007/s00114-002-0397-9

[6] A. H. Johnstone ." Chemical Education Science or Alchemy?" J Chem vol. 74 pp. 62-268, 2003. doi:10.1021/ed074p262

[7] Y.-C. Lin, D.-C. Yang, \& M.-N. Li, "Diagnosing Students' Misconceptions in Number Sense via a Web-Based Two-Tier Test. Eurasia Journal of Mathematics," Science and Technology Education, vol. 12, no.1, pp.41-55, 2016.

doi:10.12973/eurasia.2016.1420a

[8] T. W. Teo, M. T. Goh, \& L. W. Yeo, "Chemistry education research trends: 2004-2013, Chem. Educ. Res. Pract., vol. 15, pp. 470- 487, 2014. doi:10.1039/C4RP00104D

[9] J. M. Linacre, "Investigating rating scale category utility". Journal of Outcome Measurement. vol. 3, no. 2, pp. 103-122, 1999.

[10] Z. D. Kirbulut, \& O. Geban, "Using Three-Tier Diagnostic Test to Assess Students' Misconceptions of States of Matter." Eurasia Journal of Mathematics, Science and Technology Education, vol. 10, no. 5, pp. 509-521, 2014.

doi:10.12973/eurasia.2014.1128a

[11] C. F. Herrmann-Abell, \& G. E. DeBoer, "Using distractor-driven standardsbased multiple-choice assessments and Rasch modeling to investigate hierarchies of chemistry misconceptions and detect structural problems with individual items". Chemistry Education Research and Practice, vol. 12, no. 2, pp. 184-192, 2011. doi:10.1039/c1rp90023d 
[12] A. L. Chandrasegaran, D. F. Treagust, \& M. Mocerino, "The development of a two-tier multiple-choice diagnostic instrument for evaluating secondary school students' ability to describe and explain chemical reactions using multiple levels of representation." Chem. Educ. Res. Pract., vol. 8, no.3, pp. 293-307, 2007. doi:10.1039/B7RP90006F

[13] M. Başer, "Fostering Conceptual Change by Cognitive Conflict Based Instruction on Students' Understanding of Heat and Temperature Concepts. Eurasia Journal of Mathematics", Science and Technology Education, vol. 2, no. 2, pp. 96-114, 2006.

doi:10.12973/ejmste/75458

[14] T. Bond, Z. Yan, \& M. Heene, Applying the Rasch model: Fundamental measurement in the human sciences. Routledge.2020. ISBN:978-0805854626

[15] B. Sumintono, \& W. Widhiarso, ". Aplikasi Model Rasch untuk Penelitian IImu-ilmu Sosial. Cimahi: Trim Komunikata Publishing House. ISBN: 978-602-14371-1-7

[16] S. Wei, X. Liu, Z Wang, \& Wang, "Using Rasch measurement to develop a computer modeling-based instrument to assess students' conceptual understanding of matter". Journal of Chemical Education, vol. 89, no.3, pp. 335-345, 2012.

doi: $10.1021 /$ ed $100852 t$

[17] D. K., Gurel, A. Eryilmaz, \& L. C. A. McDermott, "review and comparison of diagnostic instruments to identify students' misconceptions in science". Eurasia Journal of Mathematics, Science and Technology Education, vol. 11, no. 5, pp. 989-1008, 2015. doi: 10.12973/eurasia.2015.1369a
[18] S. A. Wind, \& J. D. Gale, "Diagnostic opportunities using Rasch measurement in the context of a misconceptions-based physical science assessment". Science Education, vol. 99, no. 4, pp. 721-741, 2015.

doi: 10.1002/sce.21172

[19] Y. Xiao, J. Han, K. Koenig, J. Xiong, \& L. Bao, "Multilevel Rasch modeling of two-tier multiple-choice test: A case study using Lawson's classroom test of scientific reasoning". Physical Review Physics Education Research, vol.14, no. 2, 2014

doi:10.1103/PhysRevPhysEducRes.14.020104

[20] V. Talanquer, "How do students' reason about chemical substances and reactions? In G. Tsaparlis and $\mathrm{H}$. Sevian (Eds.), Concepts of matter in science education, vol. 12, pp. 331345, Dordrecht: Springer. doi:10.1007/978-94-007-5914-5_16

[21] J. WHill, R. H. Petrucci, T. W. McCreary, S. S.Perry, "General Chemistry (4th ed.). Upper Saddle River, New Jersey: Pearson Prentice Hall.

ISBN:9781891389603

[22] H. Barke, A. K. Hazari, \& S. Yitbarek, Misconceptions in Chemistry: Addressing Perceptions in Chemical Education. Springer: London,2009. doi:10.1007/s11422-012-9449-4

[23] R. Chang, General Chemistry: The Essential Concepts, 3rd ed.; McGrawHill: Boston, 2003. ISBN : 9780072410679

[24] D.Ebbing, Darrell, General Chemistry, 3rd ed, Houghton Mifflin, 1990 ISBN: 9780395433027 